\title{
DIAGNÓSTICO DA REALIDADE NUTRICIONAL NO ESTADO DO AMAZONAS, BRASIL. I - HIPOVITAMINOSE A.
}

\author{
Fernando Hélio ALENCAR'; Janete Seixas CASTRO'; Lúcia Kioko O. \\ YUYAMA ${ }^{1}$; Helyde Albuquerque MARINHO' ${ }^{1}$; Dionísia NAGAHAMA ${ }^{1}$
}

\begin{abstract}
RESUMO - Procedeu-se uma revisão de toda produção científica do Amazonas, da área da nutrição nas últimas décadas. A análise deste material, consubstanciada com as últimas pesquisas realizadas pelo grupo da Nutrição do INPA viabilizou a composição do diagnóstico da hipovitaminose A na região Amazônica. A investigação clínico-oftalmológica, envolveu 487 crianças de 2 a 5 anos, de ambos os sexos, oriundas das diferentes localidades amazônicas: Nhamundá, Alvarães, Anamã, Beruri e Benjamin Constant. Os níveis de retinol sérico foram determinados, exclusivamente, em 48 crianças do município de Nhamundá. A investigação clínica não evidenciou nenhum sinal e/ou sintoma pertinentes a carência de vitamina A. Níveis de retinol sérico, considerados normais e altos, foram registrados em 75,0\% e $25,0 \%$, respectivamente do universo estudado. O somatório destes resultados com as informações retrospectivas procedentes da literatura regional não permitem afirmar categoricamente a existência de hipovitaminose A como problema de Saúde Pública na região Amazônica.
\end{abstract}

Palavras-chave: Hipovitaminose A, Nutrição no Amazonas.

Diagnosis of the Nutritional Reality in Amazonas State, Brazil. I - Hypovitaminosis A.

ABSTRACT - The entire scientific production relating to nutrition in the State of Amazonas, Brazil, during the last decades was critically revised. Analysis of this material, complemented by our own recent investigations, provided the basis for the diagnosis of hypovitaminosis $\mathrm{A}$ in the Amazon Region. The clinical - opthalmological investigation involved 487 children of both sexes between two and five years old, from Nhamundá and Alvarães, Anamã and Beruri in State of Amazonas. Serum retinol was determined only in 48 children from Nhamundá municipality. The clinical inves 7 tigation did not detect any signs or symptoms indicative of vitamin A deficiency. Normal or high levels of serum retinol were found in $75 \%$ and $25 \%$, respectively, of the study sample. These re sults, when added to those derived from the regional litterature, preclude any categorical affirma tion that hypovitaminosis A constitutes a public health problem in the Amazon region.

Key-words: Vitamin A deficiency, Nutrition in Amazon.

\section{Introdução}

A vitamina $\mathrm{A}$, por interagir na composição dos pigmentos visuais, é de primordial importância para o mecanismo da visão. Sua carência prolongada pode determinar a instalação da cegueira parcial ou com evolução para a perda total e irreversível da visão (Sommer, 1982), além de induzir a uma maior suscetibilidade às infecções, por influenciar nas respostas do sistema imunológico (Ross, 1992). Tem importância também na reprodução, crescimento, integridade e diferenciação dos tecidos epiteliais especializados, bem como na modulação da expressão gênica (Olson, 1972; Petkovich, 1992). Evidências mais recentes têm demonstrado que a suplementação de vitamina A em áreas endêmicas contribui para atenuar a morbidade, sendo portanto, uma estratégia simples, de baixo custo e elevado benefício, para 
melhorar a qualidade de vida e a sobrevivência da população infantil dos países em desenvolvimento (Tomkins, 1991; Barreto etal., 1994). Há várias décadas tem sido publicada uma vasta literatura, tanto nacional como internacional, mostrando que para os países em desenvolvimento, as carências nutricionais epidemiologicamente mais importantes são: Desnutrição EnergéticoProtéica (DEP), Anemias Carenciais (deficiência de ferro, folato e B12), Hipovitaminose A, Cárie dental e Bócio endêmico. Em algumas regiões do Brasil e/ou bolsões de pobreza, estes processos carenciais cursam com tamanha agressividade que são considerados como problemas de saúde pública, desafiando as autoridades sanitárias há várias décadas (Batista Filho et al., 1981; Batista Filho \& Rossin, 1993; Dutra de Oliveira \& Marchini,1994; Santos et al.,1996). Não obstante, há registro na literatura atual demonstrando que vem se iniciando nestes últimos anos, melhoria na qualidade de vida da população infantil dos países em desenvolvimento, notadamente, no que se refere à análise evolutiva dos principais problemas de saúde infantil, tais como: pneumonia, diarréia, sarampo, tétano, coqueluche, desnutrição, bócio e hipovitaminose A (Monteiro \& Yunes, 1994; UNICEF, 1994/1995). Lamentavelmente, este horizonte de otimismo ainda não pode ser constatado para todo o território nacional. Ainda temos como referencial de distribuição nosológica, as informações do relatório de acompanhamento do II Plano Básico de Desenvolvimento Científico e Tecnológico - PBDCT (CNPq, 1980), bem como de pesquisas mais recentes que ainda destacam como problemas de saúde pública as mesmas carências nutricionais. Obviamente, as condições de saúde e nutrição das populações do Norte e Nordeste contribuíram mais significativamente para o dimensionamento e persistência deste quadro, onde ainda são assinaladas além das carências nutricionais, processos infecciosos e precariedade ambiental (Costa et al., 1981; Vannucchi \& Szarfarc, 1992; Batista Filho \& Rossin, 1993; Alencar et al., 1999). Objetivando a composição deste diagnóstico para nossa região, procedemos uma revisão evolutiva de toda a produção científica do Amazonas pertinente ao diagnóstico de hipovitaminose $\mathrm{A}$ realizada nas últimas décadas. A análise deste material, consubstanciada com as últimas pesquisas realizadas pelo Grupo da Nutrição/INPA, viabilizou o diagnóstico da realidade nutricional nos diferentes ecossistemas da Amazônia. O presente artigo refere-se, especificamente, a investigação da possível carência de vitamina A na Região Amazônica.

\section{Material e Métodos População de Referência}

O universo de estudo foi identificado por cadastramento populacional (busca ativa), envolvendo crianças das diferentes localidades amazônicas: Nhamundá $(n=79)$, Alvarães $(n=81)$, Anamã $(n=110)$, Beruri (n=96) e Benjamin Constant $(n=121)$. Foram incluídas no presente estudo, exclusivamente, as famílias residentes na região há mais de dois anos e que apresentassem crianças em 
idade igual e/ou inferior a cinco anos. Obedecendo estes critérios, o estudo clínico englobou 487 crianças, com idades compreendidas entre 2 e 5 anos, sendo posteriormente sub-amostradas para a composição do diagnóstico bioquímico.

\section{Exame Clínico}

$\mathrm{Na}$ presente pesquisa, a investigação das alterações oculares pertinentes a carência de vitamina $\mathrm{A}$ foi realizada por médico da equipe, utilizando lanterna de fluxo e intensidade luminosa ajustáveis, sendo os exames realizados em local previamente estabelecido pelas lideranças locais. A investigação clínica oftalmológica envolveu 487 crianças, de ambos os sexos e idades variando entre dois a cinco anos. $\mathrm{Na}$ definição do evento clínico, adotou-se o roteiro diagnóstico recomendado pela WHO/UNICEF (1994), segundo o qual a ocorrência de sinais e/ou sintomas compatíveis com hipovitaminose A é caracterizada como problemas de saúde pública, quando as alterações clínicas superarem os seguintes percentuais:

Cegueira Noturna
Xerose Conjuntival com Mancha de Bitot
Xerose Corneal
Ceratomalácia
Cicatriz Corneal

\section{Exame Bioquímico}

O sangue foi obtido por punção de veia do antebraço, após assepsia local, utilizando agulhas hipodérmicas descartáveis, após um período de repouso e jejum de no mínimo 10 horas. O soro foi separado logo após a coleta e acondicionado em gelo, apropriadamente protegido da luz so $\neg$ lar, sendo posteriormente armazenado sob temperatura de $-20^{\circ} \mathrm{C}$ até o momento da análise no laboratório. Os níveis de retinol sérico foram determinados exclusivamente no soro de 48 crianças do município de Nhamundá (*), pelo método espectrofotométrico de Bessey \& Lowry (1946) e modificado por Araújo e Flores (1978). Na interpretação dos resultados foram adotadas as normas da WHO/UNICEF (1994), que definem as concentrações de retinol sérico, de acordo com os seguintes pontos de corte: baixo (< $0,70 \mu \mathrm{mol} / \mathrm{L})$ e deficiente $(<0,35$ Hmol/L). Segundo a OMS (1996), a magnitude da deficiência de vitamina A pode ser caracterizada como problema de saúde pública, quando a prevalência dos níveis de retinol sérico $(<0,70 \mu \mathrm{mol} / \mathrm{L})$ em crianças maiores de um ano assumir as seguintes

$\begin{array}{ll}(\mathrm{XN}) & (1,0 \%) \\ (\mathrm{X} 1 \mathrm{~B}) & (0,5 \%) \\ (\mathrm{X} 2) & (0,01 \%) \\ \text { (X3B) } & (0,01 \%) \\ \text { (XS) } & (0,05 \%)\end{array}$

proporções:

$\begin{array}{ll}\text { Leve } & >2,0-<10,0 \% \\ \text { Moderado } & >10,-19,9 \% \\ \text { Grave } & >-20,0 \%\end{array}$




\section{Resultados e Discussão}

A análise das pesquisas desenvolvidas na Amazônia (Tab. 1) nestas últimas décadas registra os sinais clínicos da carência de vitamina A pela ocorrência de espessamento conjuntival e hiperqueratose folicular, notadamente, em crianças pré-escolares, residentes em sua maioria na área urbana de Manaus (Silva, 1959; Contente, 1963; Lowenstein, 1967; Giugliano \& Shrimpton, 1977; Giugliano et al., 1981; Giugliano et al., 1984) . Entretanto, há referência na literatura a respeito da inespecificidade destes sinais, podendo dever-se a outros processos carenciais, tais como a deficiência de folato ou de ácidos graxos (Jelliffe, 1968; Lowenstein, 1967; Sommer, 1980). De acordo com a nomenclatura atual, a identificação isolada de Xerose Conjuntival (X1A) não permite o diagnóstico específico da carência de vitamina A. Segundo os critérios da WHO/UNICEF (1994), somente a ocorrência simultânea de Xerose Conjuntival com Mancha de Bitot (X1B) é considerada como condição indicativa da deficiência de vitamina A.

Deste modo, a análise dos diagnósticos clínicos até então obtidos inviabiliza a caracterização da ocorrência de hipovitaminose A como problema de saúde pública na Região Amazônica, tanto pela fragmentação e baixa representatividade dos grupos populacionais estudados, como pela divergência dos critérios diagnósticos utilizados. Mais recentemente, Alencar (2001) e Yuyama (2002) estudaram as condições de saúde, nutrição e sobrevivência das populações dos diferentes ecossistemas Amazônicos e não registraram, pelos critérios propostos pela WHO/UNICEF (1994), sinais clínicos compatíveis com carência de Vitamina A em préescolares das localidades de Novo Airão, Barcelos, São Gabriel da Cachoeira, Nhamundá, Alvarães, Anamã, Beruri e Benjamin Constant (Tab. 1).

O diagnóstico bioquímico da carência de Vitamina A foi introduzido na Região Amazônica a partir de 1981, sendo realizado em grupos isolados, identificados aleatoriamente, praticamente circuns $\neg$ critos à área urbana de Manaus. Portanto, estes estudos não são representativos do Amazonas em sua totalidade e os resultados são na sua maioria analisados segundo a classificação do ICNND (1963), recomendada pela OPAS (1970). Deste modo, são registrados baixos níveis de retinol (< $19 \mu \mathrm{g} / 100 \mathrm{~mL})$ e elevada concentração de caroteno sérico (> $40 \mu \mathrm{g} / 100 \mathrm{~mL}$ ), respectivamente, em $15,0 \%$ e $51,0 \%$ dos operários de duas fábricas do distrito industrial de Manaus, caracterizando-se este grupo como de alto risco no aporte dietético de vitamina A (Marinho et al., 1981). Níveis inadequados de retinol e $\beta$ caroteno, compatíveis com problema de Saúde Pública, foram registrados em $36,0 \%$ e $61,0 \%$, respectivamente, do soro de 240 pré-escolares de um bairro pobre de Manaus (Marinho 1989). As pesquisas desenvolvidas mais recentemente na Região não identificam a hipovitaminose A como problema de 
saúde pública, sendo registrados níveis de retinol sérico aceitáveis (> $20 \mu \mathrm{g} /$ $100 \mathrm{~mL})$ em mais de $90,0 \%$ de préescolares de Manaus e de caroteno sérico (> $40 \mu \mathrm{g} / 100 \mathrm{ml}$ ) em mais de $76,0 \%$ do universo estudado (Alencar et al,, 1993; Moura \& Marinho, 1994). Do mesmo modo, Alencar (2001) constatou em uma comunidade da Calha do rio Amazonas (Nhamundá) que a totalidade dos pré-escolares investigados apresentava níveis de adequação > 20 $\mu \mathrm{g} / 100 \mathrm{~mL}$ (Tab. 2). No tocante à metodologia utilizada, Ramalho etal. (1995) questionaram a sensibilidade dos níveis séricos de retinol como prova diagnostica fidedigna da reserva hepática de vitamina A, evidenciandose então a necessidade de utilização de métodos mais sensíveis para o diagnóstico da deficiência marginal de vitamina $A$. Neste sentido, não há referência na literatura regional a respeito da utilização de novas técnicas de estimativa indireta dos níveis hepáticos de vitamina $\mathrm{A}$, tais como o índice de resposta relativa RDR (Relative Dose Response), bem como da sua versão modificada ou da dosagem hepática de retinol. Entretanto, sabe-se que esses dois indicadores são difíceis de realizar em estudos populacionais.

$\mathrm{Na}$ composição do diagnóstico

Tabela 1. Ocorrência de sinais e/ou sintomas clínicos pertinentes a carência Vitamina-A, registrados em diferentes grupos populacionais do Amazonas nas últimas décadas.

\begin{tabular}{|c|c|c|c|c|c|c|}
\hline \multirow[b]{2}{*}{ LOCAL } & \multirow[b]{2}{*}{ AUTORES/ANO } & \multicolumn{2}{|l|}{ UNIVERSO } & * DIAGNOSTICO & \multicolumn{2}{|c|}{ LINICO (\%) } \\
\hline & & IDADE & $\mathrm{HF}$ & EC & $\mathrm{xc}$ & MB \\
\hline Bacia Amazônica (Urbano) & Silva, 1959 & 4159 - crianças e adultos & 6,3 & 11,7 & 6,3 & 0,0 \\
\hline Manaus (Urbano) & Contente, 1963 & $185 \cdot 0$ a 14 anos & 2,5 & 0,0 & 0,7 & 0,0 \\
\hline Sete Localidades da Amazônia $\left({ }^{*}\right)$ & Lowenstein, 1967 & 2091 - adultos + crianças & 0,0 & $5,6-28,2$ & 0,0 & 0,0 \\
\hline Manaus (Urbano) & Giugliano \& Shrimpton, 1977 & 122 - pré-escolares & 44,5 & 69,7 & 0,0 & 0,0 \\
\hline Manaus (Urbano) & Giugliano et al., 1978 & $69 \cdot(7$ a 10 anos $)$ & 29,0 & 81,1 & 0,0 & 1,4 \\
\hline Manaus (Urbano) & Giugliano et al., 1981 & 191 - (crianças) & 39,0 & 74,0 & 0,0 & 0,0 \\
\hline Rio Negro (Rural) & Giugliano et al., 1984 & $121-(0$ a 6 anos $)$ & 1,6 & 43,0 & 0,0 & 0,0 \\
\hline Manaus & Marinho, 1989 & 471 - pré - escolares & 1,0 & 0,0 & 0,0 & 0,0 \\
\hline Río Negro (Novo Ai rão) & Dados Não Publicados & $108-(0$ a 5 anos $)$ & 0,0 & 0,0 & 0,0 & 0,0 \\
\hline Manaus (Urbano) & Dados Não Publicados & $528-(0$ a 5 anos $)$ & 0,0 & 0,0 & 0,0 & 0,0 \\
\hline Rio Negro (Barcelos) & Dados Não Publicados & 112- (0 a 5 anos) & 0,0 & 0,0 & 0,0 & 0,0 \\
\hline Rio Negro (São Gabriel) & Dados Não Publicados & $110-(0$ a 5 anos $)$ & 0,0 & 0,0 & 0,0 & 0,0 \\
\hline Rio Amazonas & Alencar, 2001 & $79-(0$ a 5 anos $)$ & 0,0 & 0,0 & 0,0 & 0,0 \\
\hline Rio Solimões (Alvarães) & Dados Não Publicados & $81-(0$ a 5 anos $)$ & 0,0 & 0,0 & 0,0 & 0,0 \\
\hline Anamã (Rio Solimões) & Dados Não Publicados & $110-(0-5$ anos $)$ & 0,0 & 0,0 & 0,0 & 0,0 \\
\hline Beruri (Rio Purús) & Dados Não Publicados & $96 \cdot(0-5$ anos $)$ & 0,0 & 0,0 & 0,0 & 0,0 \\
\hline Benjamin Constant & Yuyama, 2002 & $121-(0-5$ anos $)$ & 0,0 & 0,0 & 0,0 & 0,0 \\
\hline
\end{tabular}

(*) Benjamim Constant, Cruzeiro do Sul, Maués, Boa Vista, Belterra, Macapá e Mazagão.

$\left.{ }^{(\star}\right) \mathrm{HF}=$ Hiperqueratose folicular;

$E C=$ Espessamento conjuntival;

$X C=$ Xerose conjuntiva;

$M B=$ Mancha de Bitot. 
da hipovitaminose A na comunidade, é imprescindível também o conhecimento do padrão de consumo alimentar local, traduzido pela freqüência com que a criança e/ou família consomem os diferentes alimentos (recentes e/ou habituais), além da quantificação exata (análise química laboratorial e/ou em cegueira noturna, hemeralopia e xeroftalmia na Região Amazônica, como sendo devido ao elevado consumo de peixe. Obviamente, a realidade atual é outra; por ausência de política reguladora de preços e/ou estocagem, em determinadas épocas do ano, especialmente na cheia, a escassa oferta torna proibitivo o

Tabela 2. Níveis de Retinol e Caroteno Sérico registrados em diferentes grupos populacionais do Amazonas nas últimas décadas.

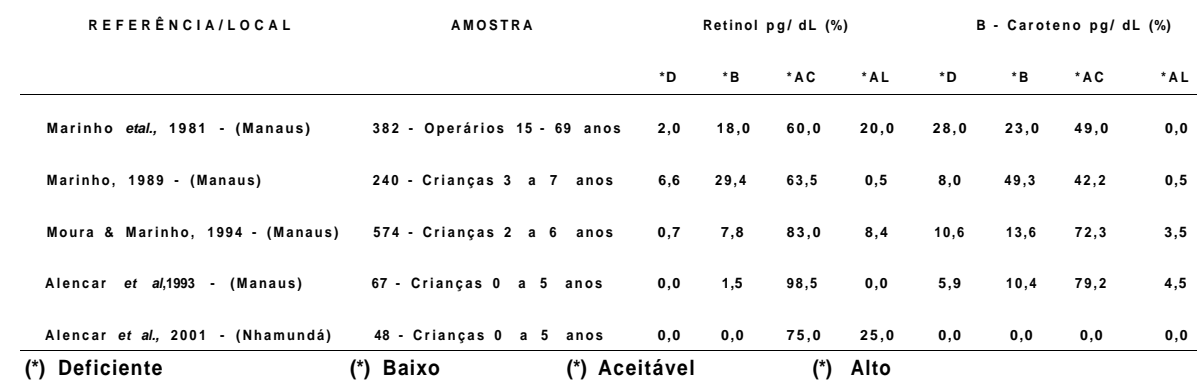

duplicata) dos alimentos ingeridos nas últimas 24 horas. O entendimento destes determinantes identificará o perfil nutricional nos níveis individual, populacional e regional, bem como viabilizará a escolha do veículo apropriado para o enriquecimento de determinado nutriente e a elaboração de programas de prevenção e intervenção nutricional na comunidade.

Amoroso (1981), Yuyama etal., (1992, 1997) referem-se, em diferentes épocas, aos cardápios amazônicos, como pobres e monótonos, sendo o peixe, o pão e a farinha de mandioca os seus principais constituintes. Neste sentido, Araújo (1956) já justificava a ótima acuidade visual do caboclo amazonense, bem como a ausência de consumo do pescado para a população urbana de baixa renda. A farinha de mandioca (Manihot esculenta Crantz), um dos principais componentes da dieta regional, notadamente para as famílias de menor poder aquisitivo, representa a principal fonte energética do cardápio amazonense. A ela são atribuídas, empiricamente, muitas propriedades nutricionais como o suprimento de vitaminas do complexo B. Durante o processo de fermentação da farinha, ocorreria a transformação do cianeto de potássio em ácido cianídrico, que tem como produto final a cianamida, um componente químico determinante da síntese do complexo B. Cientificamente, já está relativamente bem definida a composição dos carotenóides precursores da vitamina A na farinha de 
mandioca amarela (Marinho etal., 1996). Entretanto, na análise das potencialidades regionais dos nutrientes relacionados a vitamina A, além da ingestão de proteína, zinco e energia, devem ser considerados também os fatores responsáveis pela degradação da atividade pró-vitamina A dos carotenóides, tais como a variedade dos cultivares, o processamento e o armazenamento (Yuyama et al., 1999). Há registro na literatura de degradação total da atividade dos carotenóides quando a farinha de mandioca amarela é armazenada por seis meses em sacos plásticos transparentes, à temperatura ambiente e exposta à luz (Marinho et al., 1996). Nestas últimas décadas, a análise evolutiva dos inquéritos nutricionais realizados na Região Amazônica evidencia uma relativa adequação protéica, com alguns grupos populacionais recebendo praticamente o dobro da recomendação. Entretanto, o aporte energético foi extremamente limitante (Lowestein,1967; Amoroso, 1981; Shrimpton, 1973-1974; Marinho, 1989; Nagahama et al., 1990; Rocha, 1991; 1993; Yuyama et al, 1997; 1998; 1999) (Tab. 3).

Shrimpton (1973-1974), em estudo de maior abrangência sobre o consumo alimentar da população de baixa renda de Manaus (1.200 famílias), observou que a vitamina $\mathrm{A}$ e o zinco foram os nutrientes mais limitantes da dieta local. Outros autores também referem consumo inadequado de vitamina A pré-formada ou de seus precursores em diferentes grupos populacionais, exceção registrada em operários do distrito industrial de Manaus (Marinho, 1989) e de pré- escolares de baixa renda matriculados em uma creche do SESI/Manaus (Nagahama et al., 1990). Em ambos os casos, operários e pré-escolares recebiam alimentação diferenciada nas respectivas instituições, o que possivelmente explica os níveis de adequação de retinol e caroteno séricos acima da recomendação.

Paradoxalmente a esta situação, a literatura cita o potencial nutricional dos frutos amazônicos, destacando-se o abricó (Mammea americana L), buriti (Mauritia flexuosa L.f), tucumã (Astrocaryum vulgare Mart.) e a pupunha (Bactris gasipaes Kunth^, como portadores de elevado teor de caroteno (Yuyama et al., 1991; Lehti, 1993; Aguiar, 1996; Yuyama et al., 1998; Yuyama et al., 1999). Considerando que a maioria destes frutos são ingeridos "in natura", isso aumentaria significativamente a biodisponibilidade dos seus constituintes (Yuyama et al., 1999). Não obstante, é notório também na referida literatura, a ausência do hábito e/ou costume da população amazônida, notadamente a urbana, consumir frutas, legumes e hortaliças (Giugliano et al., 1981; Amoroso, 1981; Yuyama et al., 1989; Yuyama et al., 1999), o que ressalta a importância e urgência da viabilização de um programa mais agressivo de educação epidemiológica, junto a referida população, destacando as potencialidades nutricionais dos alimentos regionais. A análise destes resultados permite concluir que no estágio atual de disponibilidade de informações, não se pode confirmar a ocorrência de hipovitaminose A como 
Tabela 3. Percentagem de adequação em Calorias, Proteínas, Vitamina-A e Zinco registrados em diferentes grupos populacionais do Amazonas nas últimas décadas.

\begin{tabular}{|c|c|c|c|c|c|c|c|}
\hline Autor/ Ano & $\mathrm{N}^{\circ}$ & Faixa Etária/Categoria & $\mathrm{C}$ a I. * & Ptn.* & Vit $-A$ * & $\mathrm{Zn}$ & $P$ a d rão \\
\hline Lowsentein, 1967 & 34 & Famílias & 78 & 78,1 & 36,3 & 0,0 & - \\
\hline \multirow[t]{4}{*}{ (sete localidades) } & 29 & Famílias & 96 & 90,0 & 41,2 & 0,0 & - \\
\hline & 20 & Famílias & 72 & 108,5 & 18,7 & 0,0 & - \\
\hline & 2.091 & Todas as idades & 0,0 & 0,0 & 0,0 & 0,0 & - \\
\hline & & & 81 & 101,6 & 48,4 & 0,0 & RDA / $1989\left(^{*}\right)$ \\
\hline Amoroso, 1981 & 50 & Famílias & 47,9 & 100,0 & 35,4 & 0,0 & WHO / 1974 \\
\hline \multirow[t]{4}{*}{ Marinho et al , 1981} & 382 & Operários Fab. I & 0,0 & 0,0 & 137,0 & 0,0 & RDA / 1974 \\
\hline & & Operários Fab II & 0,0 & 0,0 & 743,0 & 0,0 & - \\
\hline & & Operários Fab III & 0,0 & 0,0 & 53,0 & 0,0 & - \\
\hline & & Operários Fab IV & 0,0 & 0,0 & 58,0 & 0,0 & - \\
\hline \multirow[t]{3}{*}{ Shrimpton, 1973-1974 } & 1.200 & Família Baixa Renda & 93,1 & 203,6 & 57,0 & 53,0 & $\mathrm{RDA} / 1974$ \\
\hline & & Família Média Renda & 92,1 & 201,0 & 71,0 & 56,0 & - \\
\hline & & Família Alta Renda & 106,0 & 222,0 & 127,0 & 75,0 & - \\
\hline Shrimpton, 1973 & 153 & Pré - escolares & 0,0 & 0,0 & 114,0 & 0,0 & $\mathrm{RDA} / 1974$ \\
\hline Marinho, 1989 & 240 & 3 a 7 anos & 59,3 & 167,0 & 62,6 & 50,0 & - \\
\hline \multirow[t]{3}{*}{ Yuyama et al., 1989} & 148 & Mães / não grávida & 76,0 & 132,0 & $85,0 \quad(\mathrm{UI})$ & 0,0 & $\mathrm{RDA} / 1980$ \\
\hline & & Gestante & 68,0 & 76,0 & $57,0 \quad(\mathrm{UI})$ & $-0,0$ & \\
\hline & & Nutriz & 61,0 & 90,0 & 43,0 & 0,0 & \\
\hline \multirow[t]{2}{*}{ Nagahama et al., 1990} & 250 & Alimentação / creche & 36,5 & 54,8 & 83,5 & 0,0 & $\mathrm{FAO} / \mathrm{OMS}$ \\
\hline & & Alimentação / total & 68,2 & 93,0 & 128,1 & 0,0 & - \\
\hline Rocha, 1991 & 64 & $<24$ meses & 37,5 & 87,5 & 50,0 & 0,0 & \\
\hline \multirow[t]{2}{*}{ Rocha et al., 1993} & 82 & Pré - escolares & 55,0 & 98,8 & 51,0 & 0,0 & RDA / 1989 \\
\hline & & Escolar & 35,0 & 59,0 & 24,0 & 0,0 & - \\
\hline Yuya m a et al,1997 & 109 & Pré - escolares & 11,0 & 78,0 & 0,0 & 21,0 & $\mathrm{RDA} / 1989$ \\
\hline \multirow[t]{2}{*}{ Yuya m a et al, 1998} & 23 & 5- zona urbana & 39,5 & 86,8 & 0,0 & 21,6 & $\mathrm{RDA} / 1989$ \\
\hline & & 18 - Zona rural & 31,9 & 52,8 & 0,0 & 11,4 & - \\
\hline \multirow[t]{2}{*}{ Yuya m a et al.,1998 } & 31 & Criança 1 a 3 anos & 32,4 & 126,1 & 0,0 & 36,7 & $\mathrm{RDA} / 1989$ \\
\hline & & Crianças 4 a 6 anos & 23,4 & 84,0 & 0,0 & 36,7 & - \\
\hline Yuyam a et al, 1998 & 44 & 182 Pré - escolares & 38,9 & 104,8 & 0,0 & 28,8 & RDA / 1989 \\
\hline Yuya $\mathrm{m}$ a et al, 1999 & 90 & 173 Pré - escolares & 30,4 & 86,8 & 0,0 & 24,7 & - \\
\hline Yuya m a et al,1999 & 59 & 140 Pré - escolares & 20,2 & 54,5 & 0,0 & 21,2 & NAS / NRC-1989 \\
\hline Yuyam a et al, 1999 & 22 & $\begin{array}{l}49 \text { P ré - e s colares } \\
4 \text { a } 6 \text { anos }\end{array}$ & 23,0 & VL & 0,0 & 13,6 & NAS / NRC-1989 \\
\hline \multirow[t]{2}{*}{ Yuya m a et al,1999 } & 109 & Barcelos Pré- escolar & 21,5 & 57,9 & 0,0 & 16,0 & NAS / NRC-1989 \\
\hline & 6 & Ajuricaba & 10,0 & 76,0 & 0,0 & 38,0 & NAS / NRC-1989 \\
\hline
\end{tabular}

problema de Saúde Pública na região Amazônica.

\section{Agradecimentos}

Ao BID/FINEP pela ajuda financeira ao desenvolvimento desta pesquisa (Processo n 64.96.0746-)

\section{Bibliografia citada}

Aguiar, J.P.L. 1996. Tabela, de composição de alimentos da Amazônia. Acta Amazonica,
26(1/2):121-126.

Araújo, C.R.C. \& Flores, H. 1978 Improved spectrophotometric vitamin A assay. Clin. Chem. 24:386

Araújo, V.A. 1956. Introdução a sociologia da Amazônia. Sérgio Cardoso, Manaus / AM. $485 \mathrm{p}$.

Alencar, F.H. 2001. Estudo das condições de saúde, nutrição e sobrevivência das populações da Calha do rio Amazonas (Nhamundá, Itapiranga e Urucurituba). Relatório FINEP/BID, Manaus. 112p.

Alencar, F.H.; Yuyama, L.K.O.; Nagahama, D.; 
Parente, R.C.P. 1999. Estudo antropométrico de pré-escolares da calha do rio Negro, Amazonas - Brasil. II Barcelos. Acta Amazonica, 20(2):293-302.

Alencar, F.H.; Marinho, H.A.; E. Nascimento, B.A. do 1993. Estudo das condições nutricional, econômica e social, de crianças pré-escolares residentes na área urbana de Manaus-AM. $45^{\circ}$ Reunião Anual da Sociedade Brasileira para o Progresso da Ciência, 119 p.

Amoroso, M.C.M. 1981. Alimentação em um bairro pobre de Manaus - AM. Acta Amazonica, vol.11(3): Suplemento:134.

Batista Filho, M.; Rossin, A. 1993. Deficiências nutricionais: Ações específicas do setor saúde para o controle. Cad. Saúde Públ., 9 (2):130- 35.

Batista Filho, M.; Lucena, M.A.F.; Coelho, H.A.L. 1981. Desnutrição proteicoenergética em três cidades brasileiras: São Luiz, Recife e São Paulo. Bol. Ofic. Sanit. Panamer., 90:48- 57.

Barreto, M.L.; Santos, L.M.P; Assis, A.M.O.; Araújo, M.P.N.; Farzentena, G.I.; Santos, P.A.B. 1994. Effect of vitamin A suplementation on diarrhoea and acute lower respiratory tract infections in young children in Brazil. Lancet, 344:228- 231.

Bessey, O.A; Lowry, O.H.; Brock. M.F; Lopea, I.A. 1946. The determination of vitamin A and carotene in small quantities of blood serum. I. Biol. Chem., 166:177-79.

CNPq/SOS. Relatório de acompanhamento do IIIPBDCT. Brasilia, 1980 apud Brasil. Secretaria de Planejamento Saúde e Nutrição; III Plano Básico de Desenvolvimento Científico e Tecnológico- (Programas em Ciências e tecnologia, 6). Brasília, 1982. 115p.

Costa, E.; Romani, S.A.M.; Batista Filho, M.; Rocha, A.N. 1981. Desnutrição recente, crônica, pregressa em quatro localidades do estado de Pernambuco, Brasil. Publ., S. Paulo, 15:211- 12 .

Contente, J.J.S. 1963. Estudo clíniconutricional em menores da cidade de Manaus-AM. Ass. Med. Bras.
$9(5): 169-80$.

Dutra de Oliveira, J.E; Marchini, J.S. 1994. Levantamento bibliográfico de estudos bioquímicos - nutricionais sobre micronutrientes realizados no Brasil. Cadernos de Nutrição, 8:31-67.

Giugliano, R.; Shimpton, R. 1977. Estudo antropométrico e clínico do estado nutricional em um grupo de crianças préescolares de Manaus-AM. Acta Amazonica, 7:389- 394.

Giugliano, R; Alburquerque. H.C. R; Shrimpton, R.; 1978. Estudo antropométrico, clínico e de padrões alimentares em um grupo de escolares de Manaus, 1976. Acta Amazônica 8: (1) 75-82.

Giugliano, R.; Giugliano, I.; Shimpton, R. 1981. Estudos nutricionais das populações rurais da Amazônia. I Várzea do Rio Solimões. Acta Amazonica, 11:773- 88.

Giugliano, R.; Shimpton, R.; Marinho, H.A.; Giugliano, I. 1984. Estudos nutricionais das populações rurais da Amazonia. II Rio Negro. Acta Amazonica, 14:427- 49.

Interdepartmental Committee on Nutrition for National Defense- ICNND. 2 ed. Washington.1963. 325p.

Jelliffe, D.B. 1968. Evaluación del estado de nutrición de la comunidad; com especial referencia o las encuestas en pas regiones em desallolo.. Organizacion Mundial de la Salud., Ginebra . 291p.

Lehty, K.K. 1993 Composição nutricional de alguns alimentos da Amazônia Brasileira. Resultados preliminares.. Série Ciência da Saúde, U.A. 1-2, p.139-47.

Lowesnstey, F.W. 1967 Report on nutritión surueys in 11 Brazilian Amazon commuᄀ nities between 1955 and 1957. Atas do Simpósio sobre a Biota Amazônica. Vol. 6 (Patologia):177- 84.

Marinho, H.A. 1989. Influencia de parasitose intestinal (Ascaris lumbricoides elou Giardia lamblia, sobre os níveis séricos de Vitamina $A$ em crianças recebendo suplementação oral de zinco elou Vitamina A. Estudo em pré-escolares de 
um bairro pobre de Manaus-AM. Dissertação de Mestrado, Curso de PÓSGraduação em Ciência de Alimentos, Universidade Federal do Amazonas, Manaus.86 p.

Marinho, H.A.; França, T.S.; Rebelo, Y.S.; Shrimpton, R. 1981. Níveis séricos de Vitamina A em operários de Manaus-AM. 11(2):347- 353 .

Marinho, H.A.; Xavier, J.J.B.N.; Miranda, R.N.; Castro, J.S. 1996. Estudos sobre carotenoides com atividades de próvitamina A em cultivares de mandioca ( Manihot esculenta crantz) em ecossistemas de terra firme de ManausAM -Brasil. Acta Amazonica, 26(3):127- 36 .

Monteiro, C.A.; Yunes, R.F. 1994. Diminui a desnutrição infantil. Ciência Hoje Espeᄀ cial, 100, 20 p.

Moura, I.P.S.; Marinho, H.A.1994. Levantamento bioquímico da prevalência da "Hipovitaminose A". Anais da $3^{\circ}$ Reunião Científica do Amazonas. 56p.

Nagahama, D.; Marinho, H.A.; Rocha, Y.R.; Ferraroni, M.J.R: Silva, N.B.; Castro, J.S.; Onety, J.A. 1990. Avaliação nutricional e alimentar de pré-escolares de uma creche de Manaus-AM e a influência no estado nutricional de sua população. Acta Amazonica, 20:119- 29.

OPAS 1970. Reunion de um grupo técnico de la OPAS sobre Hipovitaminoses A em las Americas Informe Organizacion Panamericana de la Salud. 11p.

Olson, J.A. 1972. The biological role of Vitaᄀ min A in maintaining ephithelial tissues. Israel I Maed Sci, 8:1170- 178.

Petrovich, M. 1992. Regulation of gene expres 7 sion by vitamin A, the role of retinoic acid receptors. Annu Nutr., 12:443- 71.

Ramalho, R.A.; Monteiro, R.C.; Ferreira R.M. 1995. Hipovitamonose A. Situação atual, recentes avanços. Diagnóstico e prevenção. ARS CURANDI.19p.

Rocha, R.Y 1991. Dissertação apresenta ao Programa de Pós - Graduação em Biologia Tropical e Recursos Naturais do
Convênio INPA - FUA como parte dos requesitos para obtenção do Título de Mestre em Tecnologia de Alimentos e Nutrição. 76p.

Rocha,R.Y.; Yuyama,O.K.L.; Nascimento,P.O. 1993. Perfil nutricional de pré-escolares e escolares residentes em Palmeiras do Javari, Am. Acta Amazonica 23(1):9-14.

Ross, A.C. 1992. Vitamin A status: relation to immunity and the antibody response. Proc. Soc. Exp. Biol. Med., 200-330.

Shrimpton, R. 1973-1974. Food consumption and dietary adequacy Accord incomme in 1.200 families, Manaus, AM - Brasil,. Archivos Latino Americanos de Nutritión, Vol. XXXIV (Diciembre, 1984). 4 p.

Shrimpton, R.; Giugliano, R. 1973. Consumo de alimentos e alguns nutrientes em Manaus-Am. Acta Amazonica, 9(1):117- 41 .

Silva, W. 1959. Inquérito sobre consumo de alimentos e nutrientes, avaliação nutricional e situação econômica da população amazônica. Bol. Com. Nac. Alim., 42(2):13.

Sommer, A. 1980. Manual para detecção e controle de xeroftalmia. Fundo das Nações Unidas para a infância - UNICEF, Brasília - Brasil. 22p.

Sommer, A. 1982. Nutritional blindness: xerophthalmia. New York: Oxford Univer sity Press. 14p.

Santos, L.M.P.; Batista Filho, M.; Diniz, A. da Silva. 1996. Epidemiologia da carência de Vitamina A no Nordeste do Brasil. Bol. Oficina Sanit. Panam., 120:(6).

Tomkins, A. 1991. Vitamin A and mortality: A recent review-Supported by sight sovers (Royal Commonweath Society for the Blind) and the Inthernational Vitamin $A$ consultive group. Xerophthalmia Club. Bulletin 48. October. S/P.

UNICEF. 1994/1995. Situação mundial da Infância, Fundo das Nações Unidas para a Infância.

Vannucchi, H. Freitas, M.L.S.; Szarfarc, S.C. 1992. Prevalência de anemias nutricionais no Brasil. Cadernos de Nutrição, 1:7- 26. 
WHO / UNICEF. 1994. Indicators for assessing vitamin A deficiency and their application in monitoring and and evaluation intervetion programmes; Consultation. WHO/UNICEF Geneva, 29p.

Yuyama, L.K.O.; Nagahama, D. Marinho, H.A. Vannucchi, H. 1989. Alimentação e estado nutricional de mães em diferentes estados fisiológicos de um bairro pobre de Manaus-AM. Alim Nutr., 1:13- 21.

Yuyama, L.K.O.; Favaro, R.M.D.; Yuyama, K.; Vannucchi, H. 1991. Bioavailability of viᄀ tamin A from Peach Palm (Bactris gasipaes H.B.K) and from Peach Palm (Bactris gasipaes H.B.K. and from mango (Mangifera indica L.) in rats. Nutrition Research, 11:1167-175.

Yuyama, L.K.O.; Rocha, Y.R.; Cozzolino, S.M. 1992. Composição química e percentual de adequação da dieta regional de Manaus-AM. Acta Amazonica, 22(4): 587- 593 .

Yuyama, L.K.O.; Aguiar, J.P.L.; Alencar, F.H.; Macedo, S.H.M.; Favaro, D.I.T. 1997. Avaliação nutricional da dieta de préescolares do município de Barcelos-Am. In: Congresso Brasileiro de Pediatria , 30, Rio de Janeiro. Anais do XXX Congresso Brasileiro de Pediatria. Arquivos Brasileiros de Pediatria, 49 Supl.I):145.

Yuyama, L.K.O.; Yonekura, L.; Aguiar, J.P.L.; Souza, R.F.S. 1998. Biodisponibilidade dos carotenoides do buriti (Mauritia flexuosa) em ratos. Acta Amazônica, 28(4): 409-15.

Yuyama, L.K.O.; Aguiar, J.P.L.; Macedo, S.H.M.; Yonekura, L.; Nagahama, D.; Alencar, F.H. 1999. Perfil Nutricional da dieta dos préescolares do município de Nhamundá, Acta Amazonica, 29(4): 651-654,

Yuyama, L.K.O.; Yonekura, L.; Aguiar, J.P.L.; Sousa, R.F.S. 1999. Biodisponibilidade de Vitamin-A da pupunha (Bactris gasipaes Kunth) em ratos. Acta Amazonica 29:(3), 497-500.

Yuyama,L.k.O.; 2002. Caracterização, processamento e utilização da pupunha ( Bactris gasipaes Kunth.), açaí (Euterpe oleracea Mart.) e cubiu (Solonum sessiliflorum Dunal). Finep/PPG7. Processo 64.99.0977.00.

Publicação em 08/10/2002. 
